AS TECNOLOGIAS DIGITAIS NA ESCOLA E A FORMAÇÃO DOCENTE: REPRESENTAÇÕES, APROPRIAÇÕES E PRÁTICAS DIGITAL TECHNOLOGIES IN THE SCHOOL AND TEACHER EDUCATION: REPRESENTATIONS, APPROPRIATIONS AND PRACTICES

\author{
Volumen 14, Número 3 \\ Setiembre - Diciembre \\ pp. 1-21
}

Este número se publicó el 30 de setiembre de 2014

Onilza Borges Martins

Elaine Cátia Falcade Maschio

Revista indizada en REDALYC, $\underline{\text { SCIELO }}$

Revista distribuida en las bases de datos:

CATÁLOGO DE LATINDEX, IRESIE, CLASE, DIALNET, DOAJ, E-REVIST@S, SHERPA/ROMEO, QUALIS, MIAR

Revista registrada en los directorios:

ULRICH'S, REDIE, RINACE, OEI, MAESTROTECA, PREAL, CLACSO 


\title{
AS TECNOLOGIAS DIGITAIS NA ESCOLA E A FORMAÇÃO DOCENTE: REPRESENTAÇÕES, APROPRIAÇÕES E PRÁTICAS \\ DIGITAL TECHNOLOGIES IN THE SCHOOL AND TEACHER EDUCATION: REPRESENTATIONS, APPROPRIATIONS AND PRACTICES
}

\author{
Onilza Borges Martins ${ }^{1}$ \\ Elaine Cátia Falcade Maschio²
}

\begin{abstract}
Resumo: O texto discute a relação entre formação de professores e tecnologias digitais na escola. Procura compreender as representações, apropriações e práticas de professores da educação básica, analisando criticamente a formação docente para o uso das novas tecnologias na escola. O universo da pesquisa contemplou instituições municipais públicas da cidade de Curitiba e região metropolitana, do Estado do Paraná, responsáveis pelas séries iniciais do Ensino Fundamental. Estas instituições receberam ferramentas pedagógicas digitais como notebooks e lousas interativas. A metodologia utilizada foi de abordagem qualitativa, realizada mediante a aplicação de questionários com perguntas fechadas e abertas. Os resultados obtidos tornaram evidente a necessidade sentida pelos sujeitos escolares, em especial os professores, de uma prática pedagógica transformadora a partir do uso das tecnologias digitais. A falta de aportes teóricos, técnicos e pedagógicos, necessários ao processo de formação docente para o uso das novas tecnologias na escola, foi um dos aspectos que configuraram as dificuldades em introjetar novas práticas pedagógicas no processo de ensino e aprendizagem do contexto analisado.
\end{abstract}

Palavras-chave: ESCOLA PÚBLICA BASICA, TECNOLOGIAS, PROFESSORES, BRASIL

Resumen: El texto discute la relación entre formación de maestros y tecnologías digitales en la escuela. Busca comprender las representaciones, apropiaciones y prácticas de profesores de la Educación Básica, analizando críticamente la formación docente para el uso de las nuevas tecnologías en la escuela. El universo de la investigación contempló escuelas públicas de la ciudad de Curitiba y región metropolitana, en el Estado de Paraná, responsables de los años iniciales de la Escuela Primaria. Estas instituciones recibieron herramientas pedagógicas digitales como ordenadores portátiles y pizarras interactivas. La metodología utilizada fue cualitativa y realizada mediante la aplicación de cuestionarios con preguntas cerradas y abiertas. Los resultados ponen de manifiesto la necesidad sentida por los actores escolares, especialmente los maestros, de una práctica pedagógica transformadora a partir del uso de las tecnologías digitales. La falta de aportes teóricos, técnicos y pedagógicos, necesarios al proceso de formación docente para el uso de las nuevas tecnologías en la escuela, fue uno de los aspectos que configuraron las dificultades en asimilar nuevas prácticas pedagógicas al proceso de enseñanza y aprendizaje del contexto analizado.

Palabras-clave: ESCUELA PÚBLICA BÁSICA, TECNOLOGÍAS, DOCENTES, BRASIL

\footnotetext{
1 Pós-Doutora em Educação pela Universidade Autônoma de Barcelona. Coordenadora do Mestrado em Educação-UNINTER, Brasil. Correio eletrônico: onilza.m@grupouninter.com.br

2 Doutora em Educação pela Universidade Federal do Paraná. Professora do Centro Universitário Internacional-UNINTER, Brasil. Correio eletrônico: elaine.m@grupouninter.com.br
}

Ensayo recibido: 5 de febrero, 2014

Devuelto para corrección: 21 de julio, 2014

Aprobado: 31 de julio, 2014 
Abstract: The text discusses the relationship between teacher education and digital technologies in the school. It tries to understand the representations, appropriations and practices of elementary school teachers, while critically analyzing teacher education for the use of new technologies in the school. The universe of the research included public schools in the city of Curitiba and its metropolitan region in the state of Paraná, which are responsible for the teaching of the early grades of Elementary Education. Such institutions receive digital pedagogical tools such as laptop computers and interactive whiteboards. The methodology is based on a qualitative approach and it was performed by means of questionnaires given with closed-ended and openended questions. The results found made clear the need felt by the school subjects, especially by the teachers, for a transforming pedagogical practice based on the use of digital technologies. The lack of theoretical, technical and pedagogical contributions, which are necessary to the process of teacher education for the use of new technologies in the school, was one of the aspects that represented the difficulties to incorporate new pedagogical practices in the teaching and learning process of the analyzed context.

Keywords: PUBLIC SCHOOL, TECHNOLOGIES, TEACHERS, BRAZIL.

\section{Introdução}

As reflexões em torno das práticas pedagógicas no âmbito escolar têm permitido a produção de inúmeras investigações sobre a produção das culturas escolares. Com relação à escola contemporânea, a introdução das Tecnologias de Informação e Comunicação (TIC) leva os pesquisadores da educação a investigar e debater sobre a transformação dos modos como a escola ensina, e as formas como os alunos aprendem no contexto dos avanços tecnológicos digitais.

O presente texto, vinculado a pesquisa intitulada "As novas tecnologias educacionais na escola e a produção da cultura escolar: representações, apropriações e práticas de ensinar e aprender", desenvolvida junto ao núcleo de estudos sobre Formação Docente e Novas Tecnologias, do Programa de Pós-Graduação Stricto Sensu em Educação do Centro Universitário Internacional, Paraná/Brasil, procura investigar o cotidiano da escola no contexto da cibercultura. Compete identificar e compreender as representações, apropriações e as práticas dos professores quanto a utilização das tecnologias digitais na sala de aula. Pretende ainda, averiguar como a formação do docente tem contribuído para a produção de uma prática pedagógica diferenciada, tendo em vista a introdução das novas tecnologias educacionais nas escolas de educação básica.

Ao lançar um olhar sobre as rupturas e as permanências da escola ao longo da sua existência histórica, optou-se pela metodologia da pesquisa qualitativa, a qual orientou o levantamento do campo empírico. De acordo com Chizzotti (2013, p. 28) a pesquisa qualitativa "implica uma partilha densa com pessoas, fatos e locais que constituem objetos de pesquisa, para extrair desse convívio os significados visíveis e latentes que somente são perceptíveis a uma atenção sensível". 
Deste modo, efetuou-se uma investigação em escolas públicas, responsáveis pelas séries iniciais do Ensino Fundamental - portanto, da rede municipal de ensino - da cidade de Curitiba no Paraná e da região metropolitana. Participaram da investigação 24 professores atuantes na educação de nível básico, os quais já dispunham e utilizavam algum tipo de recurso digital em suas aulas.

A coleta das informações foi feita por meio de dois questionários organizados com perguntas abertas e fechadas. O primeiro instrumento de coleta de dados da investigação foi um questionário contendo cinco perguntas fechadas, o qual visou conhecer quais tecnologias os professores tinham disponíveis na escola, qual o sistema operacional dos computadores e de que modo esses recursos eram por eles utilizados.

O segundo instrumento, também em forma de questionário, continha dez perguntas abertas referentes ao uso da tecnologia digital nas aulas. Este questionário procurou abordar informações que pudessem caracterizar o perfil dos docentes entrevistados, questões referentes à formação inicial e continuada dos professores, aspectos sobre a apropriação dos recursos digitais em sala de aula e aspectos que configuravam as práticas docentes, enfatizando as questões positivas e negativas quanto ao uso das tecnologias digitais.

Um dos critérios para a participação dos docentes na pesquisa foi a aceitação do preenchimento dos questionários, garantindo o anonimato dos depoentes. Por isso, os professores efetuaram o registro de seus nomes nas fichas específicas para o registro de seus dados pessoais, anexo aos questionários. Portanto, no decorrer do texto esses nomes não foram identificados, pois optou-se pela identificação alfanumérica: P1, P2, P3 e assim sucessivamente.

A caracterização dos sujeitos pesquisados foi evidenciada mediante as informações dos questionários, dos quais foi possível observar que os professores entrevistados dispunham de computadores portáteis (notebooks) e lousas interativas digitais. Esses recursos foram inseridos nas escolas onde os sujeitos atuavam, no decorrer do ano de 2012.

Ainda quanto ao perfil dos professores participantes da pesquisa, foi possível verificar que se tratavam de profissionais do gênero feminino, formados no curso de Pedagogia com especialização nas áreas de Psicopedagogia, Educação Especial e Gestão Escolar. Em relação ao tempo de serviço no magistério, constatou-se que o mesmo variava de dois a vinte três anos de atuação, sendo cinco professoras entre dois a 
dez anos de atuação; quatorze professoras entre dez a vinte anos de atuação e cinco professoras que somavam mais de vinte anos de experiência docente nas séries iniciais do Ensino Fundamental.

Os questionamentos que nortearam a presente investigação foram esses: qual a representação dos professores quanto o uso das novas tecnologias na escola? Como eles se apropriavam dessas tecnologias digitais no cotidiano escolar? Como essa apropriação possibilitava superar ou manter as práticas escolares "tradicionais"? A formação docente para o uso das novas tecnologias contribuiu para a produção de outras práticas pedagógicas?

Buscando compreender as representações, as apropriações e a instituição de novas práticas educativas a partir do uso das novas tecnologias educacionais, a pesquisa fundamentou-se em autores como Chartier (1991), Kenski (2007) e Lévy (1999). Os estudos de Chartier (1991) contribuíram para compreender as representações e as apropriações dos professores, a partir do entendimento de que a representação é a percepção social, a imagem do presente que foi construída através das práticas culturais (escolares, sociais, políticas). Assim, pretendeu-se investigar as representações, ou seja, os modos como os professores pensam, olham e constroem a realidade da sala de aula a partir do uso das novas tecnologias digitais.

Do mesmo modo, o termo apropriação é entendido a luz das reflexões do autor. A apropriação é a interpretação das representações e prescrições formalizada nas práticas. Portanto, pode-se dizer que as práticas pedagógicas dos professores mediante a utilização das novas tecnologias na escola configuram os modos como as prescrições legais foram apropriadas e junto as representações dos sujeitos foram transformadas em práticas.

Os professores das séries iniciais da educação de nível básico entrevistados foram porta-vozes de experiências pedagógicas singulares, que informaram os significados atribuídos no cotidiano da escola. Tentando compreender como essas experiências foram materializadas nas práticas, procurou-se observar como as prescrições para o uso das novas tecnologias educacionais foram apropriadas e assumiram por vezes, outros significados.

Os estudos de Kenski (2007, p. 19) contribuíram para compreender que as tecnologias sempre se fizeram presentes na escola, pois ela "engloba a totalidade de coisas que a engenhosidade do cérebro humano conseguiu criar em todas as épocas, 
suas formas de uso, suas aplicações". Mas a autora também elucidou que as novas tecnologias se referem especificamente "aos processos e produtos relacionados com o conhecimento provenientes da eletrônica, da microeletrônica e das telecomunicações" e também "seu principal espaço de ação é virtual e sua principal matéria-prima é a informação" (Kenski, 2007, p. 25).

Barreto (2010, p. 12) esclarece que as novas tecnologias educacionais derivam das Novas Tecnologias de Informação e Comunicação, porque foram (re) contextualizadas no espaço escolar. Nesta direção, entende-se que as novas tecnologias só são educacionais porque são utilizadas na escola como mediação da prática pedagógica, e porque servem a objetivos escolares constituindo-se parte integrante do programa curricular.

Assim, o presente texto - dividido em duas partes - apresenta por meio dos resultados da pesquisa de campo, as representações, apropriações e a formação de professores no uso das novas tecnologias digitais na escola de nível básico. A primeira parte do texto pretendeu compreender as representações e apropriações dos professores que usufruem na sua prática diária de recursos digitais como netbooks e lousas interativas; a segunda discute a formação docente (inicial e continuada) como contributo para a produção de novas práticas pedagógicas ou para a manutenção dos mesmos modos de ensinar e aprender.

\section{Para compreender as representações, apropriações e práticas de ensinar na escola por meio das tecnologias digitais}

Para além dos laboratórios de informática, a introdução dos computadores portáteis na sala de aula implica na aproximação mais rápida do aluno à cultura digital. A possibilidade de a escola acessar de forma mais célere a cultura midiática, faz com que muitos profissionais e pesquisadores da educação reflitam sobre os aspectos positivos e negativos da práxis educativa, considerando o contexto da cibercultura.

O termo cibercultura é aqui entendido como um conjunto de elementos associados às formas de comunicação mediadas pelos espaços virtuais, ou seja, pelos ciberespaços. De acordo com Lévy (1999, p. 94), a cibercultura se desenvolve junto ao crescimento dos ciberespaços que se constituem como "espaço da comunicação aberto pela interconexão mundial dos computadores e das memórias dos computadores".

Os ciberespaços são lugares de veiculação da cibercultura. Eles estabelecem uma multiplicidade de conexões, capazes de constituir novas práticas de comunicação. Essas 
novas possibilidades de comunicação, redimensionam as formas como os sujeitos se apropriam do conhecimento produzido na e pela sociedade. A cibercultura, como cultura derivada da mediação e das apropriações junto às tecnologias digitais, trata-se de um fenômeno contemporâneo. Assim, ela é constituída por práticas comunicacionais, culturais e educacionais produzidas concomitantes aos avanços das Tecnologias de Informação e Comunicação.

Mesmo neste novo contexto, é relevante a imposição sobre a escola da tarefa de transmitir os conhecimentos historicamente acumulados. Contudo, tendo em vista os modos como a produção e a circulação das ciências e da cultura tem se processado na sociedade contemporânea, marcada pelos avanços tecnológicos digitais, "surgiram novas referências culturais que exigiram a necessidade do domínio de códigos diferentes para as leituras e interações com a realidade" (Martins, 2008, p. 68).

Assim, esse conjunto de conhecimentos é apreendido por meio de novas práticas pedagógicas. Por isso, entende-se que as formas como o conhecimento é transmitido e apreendido se modificam, se renovam a medida que as novas tecnologias são introduzidas no âmbito educacional, sem que a escola perca de vista a sua função no processo de formação humana. Considera-se que a escola não é apenas um lugar de transmissão de conhecimentos, mas um lugar de produção de cultura, ou de culturas.

Ao voltar nosso olhar para o interior da sala de aula, é possível perceber como a cultura escolar tem sido produzida. Segundo Forquin (1993, p. 167), a escola tem características, ritmos e linguagens próprias. Mas também, conforme afirma Viñao (2000, p. 32), as instituições escolares são constituídas por aspectos relacionais externos e internos.

Sem dúvida, um dos principais aspectos externos a influenciar a escola contemporânea tem sido o avanço das Novas Tecnologias de Informação e Comunicação. Os computadores têm extrapolado os espaços sociais e avançado para o espaço escolar da sala de aula.

Aos poucos, os lugares destinados aos laboratórios de informática nas escolas estão dando lugar a algum tipo de equipamento digital que integra o próprio espaço da sala de aula. Em algumas escolas, inclusive da rede pública de ensino, os alunos têm disponíveis computadores individuais ou tablets, de modo que o seu manuseio ocorre simultaneamente nas aulas. 
Inevitavelmente, essa nova disposição material e espacial tem transformado a prática pedagógica, principalmente no que se refere ao tempo escolar e ao processo de ensino aprendizagem. As atividades desenvolvidas em laboratórios de informática exigiam do professor a separação de parte do tempo do planejamento e o deslocamento dos sujeitos para outro espaço que não fosse aquele da sala de aula. Já a introdução do computador no contexto das atividades diárias da sala de aula, redimensiona o uso deste recurso tecnológico, integrando na própria aula os computadores portáteis e reordenando os espaços e os tempos escolares.

Assim, os equipamentos digitais portáteis (laptops, netbooks, tablets, entre outros) passaram a compor o cenário material da escola e dividir o espaço com os demais objetos da sala de aula, como por exemplo, o quadro negro e os livros escolares. Essa talvez seja a principal diferença entre os laboratórios fixos de informática, pois a flexibilização proporcionada pelos recursos digitais portáteis, possibilita sua utilização em qualquer tempo e espaço da aula. Neste caso, a possibilidade de o computador ser considerado um recurso de medição pedagógica integrado às atividades escolares diárias, e não apenas um instrumento de pesquisa ou um suporte de jogos educativos, deve ser considerada como aspecto relevante à prática docente.

No Brasil, entre os recentes programas que orientam a introdução das tecnologias digitais na escola, mais especificamente dos laptops educacionais em sala de aula, está aquela que tem sido regulamentada pela Resolução FNDE/CD № 17 de junho de 2010, a qual:

Estabelece normas e diretrizes para que os Municípios, Estados e o Distrito Federal se habilitem ao Programa Um Computador por Aluno - PROUCA, nos exercícios de 2010 a 2011, visando à aquisição de computadores portáteis novos, com conteúdos pedagógicos, no âmbito das redes públicas da educação básica. (Fundo Nacional de Desenvolvimiento da Educaçao [FNDE], 2010, párr. 1)

Sob a égide da mudança e da atualização dos processos de ensino e aprendizagem na escola junto aos avanços da sociedade, a adoção das tecnologias digitais, principalmente dos computadores no contexto escolar, tem sido considerada pela mesma legislação como uma estratégia que visa:

(...) melhorar a qualidade dos processos de ensino aprendizagem nas escolas públicas brasileiras, por meio da universalização do uso de tecnologias da 
informação e da comunicação (TIC) no sistema público de ensino, que permitam a utilização e o acesso individual dos alunos a conteúdos e instrumentais digitais de qualidade para uso pedagógico, de forma autônoma e colaborativa, aumentando com isso a permanência e o crescimento dos alunos da educação básica nos sistemas federal, estadual e municipal. (Fundo Nacional de Desenvolvimiento da Educaçao [FNDE], 2010, párr. 4)

O uso do computador no contexto escolar atual, embora ainda incipiente, tem gerado amplo impacto sobre a educação, criando-se novas formas de aprender e acessar o conhecimento. Nesse processo, merece especial ênfase, as novas maneiras como professor e aluno se relacionam - como representam e como se apropriam - dos recursos digitais.

Ocorre muitas vezes, que os computadores são inseridos nos contextos escolares como máquinas, em que se pressupõe do professor e dos alunos apenas o seu conhecimento instrumental e técnico. Contudo, conforme afirma Lévy, os computadores não são somente "instrumentos de comunicação, de pesquisa de informações, de cálculo, de produção de mensagens (textos, imagens, som) a serem colocados nas mãos dos estudantes" (Lévy, 1999, p. 174).

No universo das escolas pesquisadas, os professores entrevistados declararam que tinham disponíveis para as atividades em sala de aula, conforme apresenta o gráfico 1, as seguintes tecnologias digitais:

\section{Gráfico 1}

Tecnologias disponíveis nas escolas pesquisadas

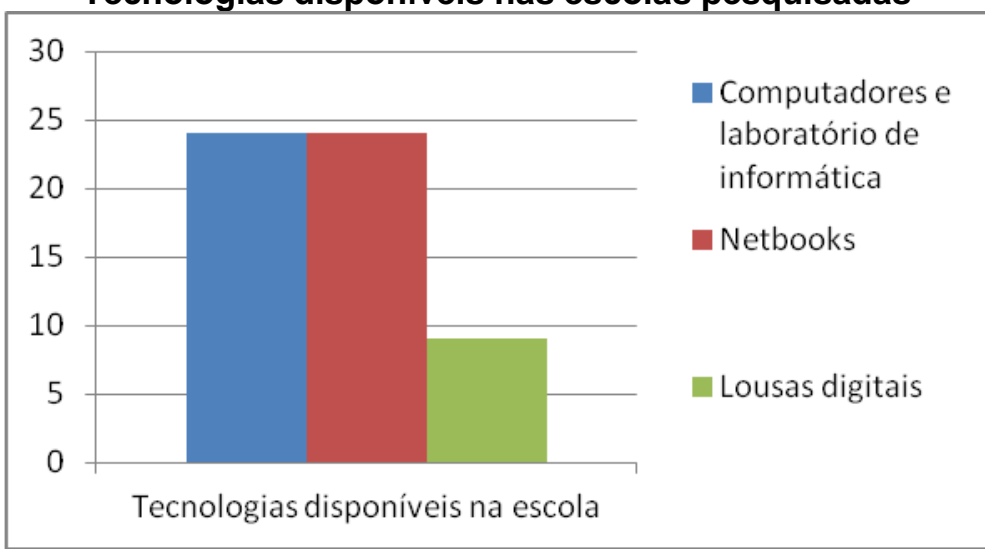

Fonte: Resultado da pesquisa realizada em escolas públicas em 2013. 
Observa-se que os 24 professores entrevistados tinham disponibilidade para 0 trabalho pedagógico diário na escola os computadores, localizados nos laboratórios de informática, mas também os netbooks que poderiam ser deslocados para qualquer espaço da escola, principalmente para a sala de aula. Assim, cada aluno poderia dispor do seu próprio aparelho para realizar as atividades.

Foram questionados ainda os entrevistados sobre qual o sistema operacional dos computadores disponíveis na escola. O resultado apontou que 12 professores utilizavam o sistema Windows, seis o Linux e seis ambos, o Windows/Linux. O uso de software livre nas escolas públicas do Estado do Paraná/Brasil ocorreu, de acordo com Bonilla (2010), desde o decreto de 29 de outubro de 2003. Esta data que marca a adesão de software livre como política pública para o ensino básico paranaense, configurou o estado um dos principais usuários de software livre do país. Ainda assim, observa-se que o Windows configura-se como sistema operacional predominante também nas escolas públicas.

Quanto ao acesso à internet, dos docentes entrevistados, apenas quatro professores declararam que a escola não dispunha desta rede. O restante dos professores revelou ter disponível o acesso a internet, mas com inúmeras dificuldades para o seu funcionamento, seja pela lentidão, interrupção do processo, e ainda, impossibilidade de acesso. Esses problemas levaram alguns professores a declararem que raramente é possível utilizar programas online nas aulas.

Essa afirmação dos docentes apresenta indícios da forma como os recursos digitais são utilizados na escola. Diante da impossibilidade de acesso à internet no ambiente escolar, e consequentemente na sala de aula, entende-se que a apropriação dos computadores e lousas interativas digitais, por exemplo, poderia se restringir ao trabalho com software educativos instalados nas máquinas.

Para Kenski:

A Internet potencializa as possibilidades de acesso às informações e a comunicação da escola com todo o mundo. Por meio da "rede das redes", a escola pode integrarse ao universo digital para concretizar diferentes objetivos educacionais. No entanto, para que a escola possa estar conectada ao ambiente tecnológico das redes é preciso, antes de tudo, possuir infraestrutura adequada: computadores em número suficiente, de acordo com a demanda prevista para sua utilização; modems e formas diversificadas e velozes de conexão (via telefone, cabo, rádio). (2012, p. 71) 
Observou-se pelas respostas dos professores que a maioria das escolas ainda não possui infraestrutura suficiente para efetivar um ensino baseado na utilização das novas tecnologias, principalmente aquelas que pressupõem o uso ininterrupto e irrestrito da internet. Por vezes, o incremento do ambiente educativo com equipamentos tecnológicos digitais é efetuado sem que a infraestrutura seja adequada, comprometendo o bom andamento das aulas e a concretização dos objetivos que a utilização dos novos recursos tecnológicos possibilitariam alcançar.

$\mathrm{Na}$ sondagem sobre as representações e apropriações dos professores por meio dos questionários, verificou-se que mesmo diante dos problemas de infraestrutura, o computador é amplamente utilizado. A principal função dele, declarada pelos docentes, é auxiliar a preparação de aulas dinâmicas e interessantes, como mostra o gráfico 2.

Gráfico 2

Utilização do computador pelo professor

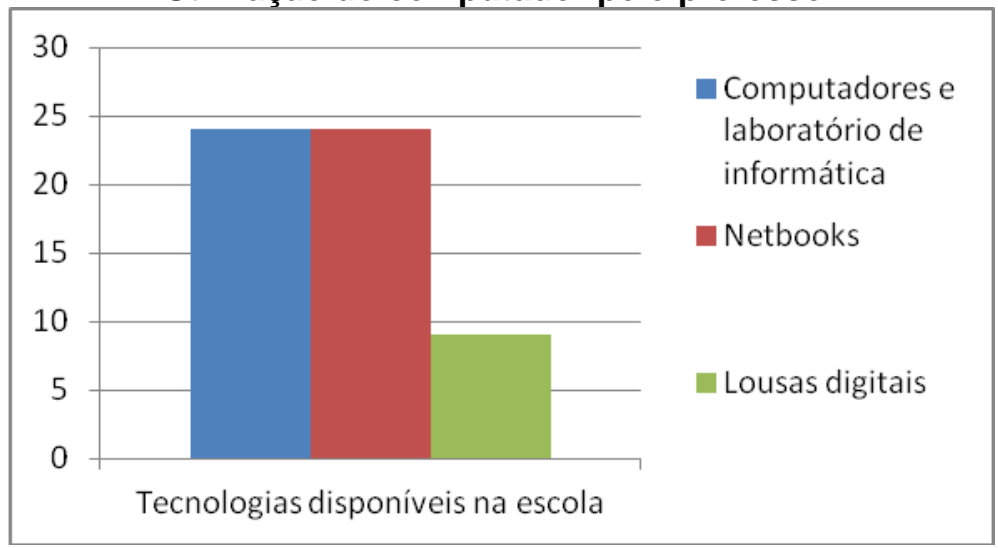

Fonte: Resultado da pesquisa realizada em escolas públicas em 2013.

A outra questão observada na apropriação dos recursos digitais foi a questão do espaço. Considerou-se como o espaço da sala de aula foi reordenado pelos professores para agregar as novas tecnologias educacionais aos materiais já existentes na escola.

Antes de discutirmos as repostas dos professores, cabe retomar à discussão de Kenski sobre a relação entre novas tecnologias e espaço escolar. Para a autora:

As tecnologias redimensionam o espaço da sala de aula em, pelo menos, dois aspectos. O primeiro diz respeito aos procedimentos realizados pelo grupo de alunos e professores no próprio espaço físico da sala de aula. Neste ambiente a possibilidade de acesso a outros locais de aprendizagem - bibliotecas, museus, centros de pesquisas, outras escolas etc... com os quais os alunos e professores 
podem interagir e aprender - modifica toda a dinâmica das relações de ensino aprendizagem. Em um segundo aspecto, é o próprio espaço físico da sala de aula que também se altera. (Kenski, 1998, p. 70)

Concordando com as considerações da autora, é possível observar no universo escolar investigado a alteração do espaço escolar nas duas perspectivas. Quanto a primeira, constatou-se pelas respostas dos entrevistados que por meio da lousa interativa digital e dos netbooks, os alunos podem acessar um universo amplo de informações, principalmente aqueles propiciados pelos ambientes de aprendizagens virtuais, quando conseguem acessar a internet. Além dos software e games educativos, os dois recursos inseridos em sala de aula permitem desenvolver novos formatos de atividades interativas. Por meio dos ciberespaços, como blogs e sites, podem acessar uma variedade de hipertextos, e-books ou outros arquivos virtuais.

A possibilidade de interação e a multiplicidade de recursos audiovisuais deixam professores e alunos atentos diante da possibilidade de apreender por meios que extrapolam os modos tradicionais de transmissão do conhecimento escolar. Para os professores, a imagem construída sobre estas tecnologias foi revelada como importante ferramenta para a mudança de suas práticas e para o avanço da qualidade do processo ensino aprendizagem.

(...) a escola precisa ir além do ensino de informática com foco em conhecimentos básicos sobre computadores, usos de aplicativos, programas de edição de texto, jogos educativos, etc. $O$ foco precisa direcionar-se para além da simples operação do equipamento, voltando-se para a possibilidade de os estudantes poderem se valer das informações disponibilizadas nesse espaço digital. Desde muito cedo em suas vidas escolares, os estudantes precisam ter acesso a computadores e participar de práticas educacionais que requeiram o uso de tecnologias da informação, com a perspectiva de um letramento digital em vista. (Soares, Valentini e Pescador, 2013, p. 155)

No que se refere ao segundo aspecto apontado pelas autoras, observou-se na fala de alguns professores, que declararam dispor da lousa interativa digital, que a apropriação deste recurso demandava a reorganização da sala de aula. Na disputa com o quadro negro pela localização central e visível a todos os alunos, a lousa digital foi 
disposta, em alguns casos, na parede ao fundo da sala. Assim, as carteiras deveriam ser reordenadas de modo que todos os alunos pudessem visualizá-la, se posicionando em frente a ela.

Verificou-se também nos depoimentos, a reorganização do espaço em função, até mesmo, da falta de espaço na escola para novos objetos. Na maioria dos casos, a lousa foi instalada na sala de aula ocupada diariamente pela turma, mas também houve outros em que a lousa foi instalada em uma sala específica da escola, como uma espécie de uma segunda sala de informática.

Conforme os depoimentos dos professores como se pode visualizar no gráfico 3 , as novas tecnologias são tomadas como instrumentos auxiliares que enriquecem as aulas.

\section{Gráfico 3}

Representação dos professores sobre a tecnologia digital

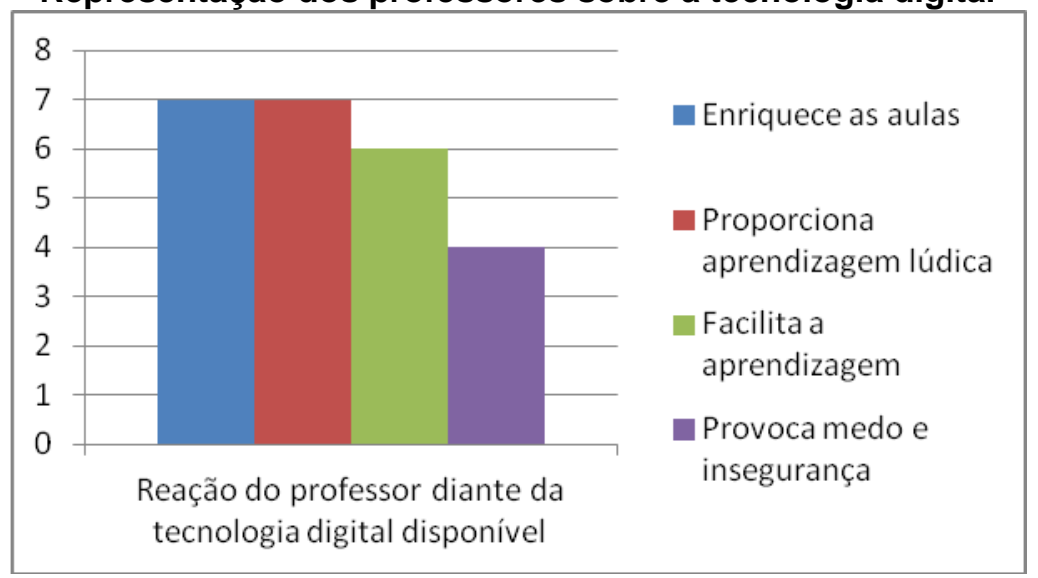

Fonte: Resultado da pesquisa realizada em escolas públicas em 2013.

Algumas falas selecionadas revelaram esses aspectos:

O acesso à multimídia me proporciona a oportunidade de trazer com frequência vídeos, documentários, filmes, músicas, que tornam os conteúdos mais prazerosos para as crianças (P2).

A lousa interativa, de acordo com o conteúdo, enriquece o meu planejamento (P7).

Foi uma novidade utilizá-la, nos dá a oportunidade de enriquecer os conteúdos com vídeos, ilustrações, etc. (P15). 
Percebe-se que as (TIC) são inseridas e integradas às práticas pedagógicas diárias dos professores como recursos que contribuem para o processo de construção de conhecimentos dos alunos. Contudo, são apropriadas de modo complementar às atividades trabalhadas ainda que de forma tradicional. Por outro lado, não raro é encontrar professores que só utilizam os computadores para propor cópia de texto ou ilustrar as aulas com vídeos e imagens.

Além disso, alguns docentes vincularam o uso dessas tecnologias como divertida e lúdica. A inserção das tecnologias digitais na sala de aula proporciona um aumento no uso de softwares de jogos educativos. Quando questionados sobre a contribuição das tecnologias digitais nas aulas, alguns declararam:

Excelente, os resultados com as crianças já aparecem em curto prazo. Eles interagem, participam, aprendem e são solidários uns com os outros nas faces mais difíceis de jogos, por exemplo (P1).

Acho que faz parte desta geração, é inerente a ela e nos ajuda a trabalhar com ferramentas pedagógicas que as crianças adoram. Elas aprendem, fazem atividade, com prazer, pois pensam que estão brincando, e, de fato, o lúdico dessas atividades com o uso da tecnologia é acentuado (P9).

É altamente atrativa para as crianças, elas se concentram mais, e aprendem brincando, é o caso dos jogos (P12).

A lousa digital é maravilhosa. Além de amar e se divertir muito, os alunos aprendem mais rápido os conteúdos e com atividades divertidas através de histórias contadas por personagens (P21).

A inserção das tecnologias digitais numa perspectiva de transformação deve contribuir para a mudança da prática pedagógica. É necessário reconfigurar o espaço da sala de aula e o redimensionamento da concepção e formação dos professores sobre o uso das novas tecnologias educacionais. Tudo isso, contribui para mudanças na própria cultura escolar instituída.

A substituição de uma tecnologia simples por outra mais complexas (e.g., quadronegro e giz por lousa interativa) pode indicar progresso tecnológico, mas não 
garante por si só o aprimoramento da aprendizagem dos alunos. De fato, se a metodologia educacional tradicional for mantida, pode-se prever pouca ou nenhuma variação no rendimento escolar dos alunos, independentemente do emprego de tecnologias educacionais sofisticadas (como suportes às aulas presenciais ou na EAD) (Ribeiro, Oliveira, Mill, 2013, p. 154).

A produção de uma mudança significativa das práticas pedagógicas na escola não é garantida somente pela introdução dos novos recursos tecnológicos, e muito menos na utilização técnica de determinadas ferramentas. É necessário que a comunidade escolar procure compreender todo o potencial das novas tecnologias educacionais. Para isso, torna-se fundamental que haja uma formação inicial e continuada dos professores de maneira sólida e comprometida. A escola também precisa estabelecer um projeto pedagógico com objetivos claros, envolvendo as necessidades dos alunos no processo de aquisição do conhecimento produzido em uma sociedade cibercultural.

O incipiente processo de inserção das novas tecnologias educacionais na escola determina o modo como professores e alunos se apropriam delas. Com relação à apropriação das novas tecnologias, o mesmo pode ser observado no gráfico 4, quando os professores foram questionados sobre a forma como as utilizam.

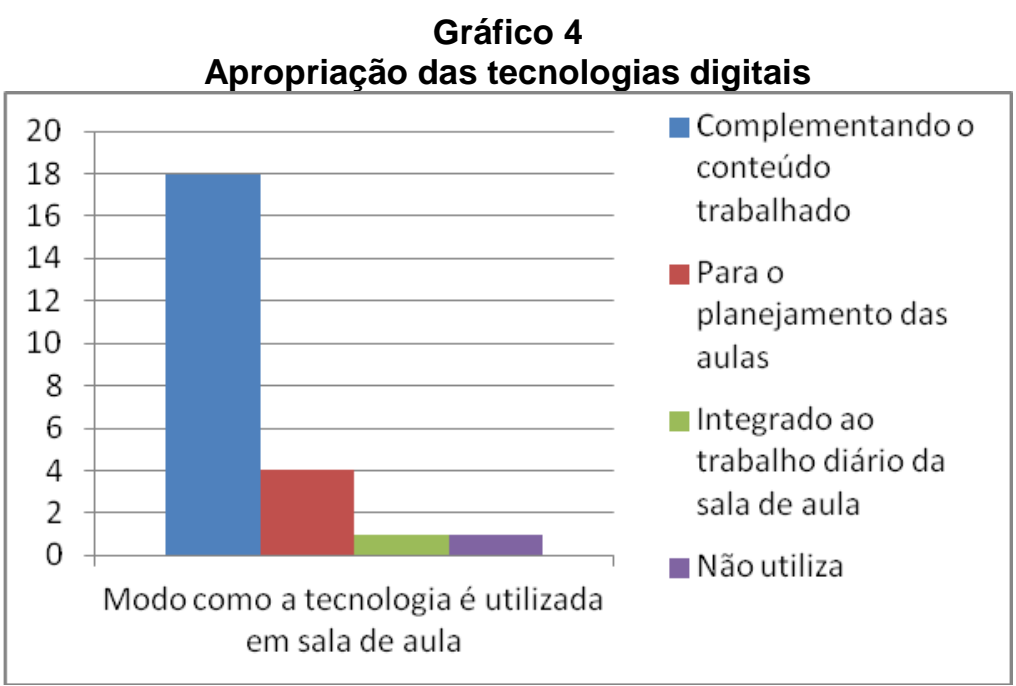

Fonte: Resultado da pesquisa realizada em escolas públicas em 2013.

O fragmento da fala de um dos docentes entrevistados ilustra o modo como as novas tecnologias são apropriadas à prática pedagógica tradicional. 
Utilizo essa tecnologia mais para enriquecer as aulas. Nela podemos passar vídeos sobre um determinado assunto, jogos com atividades de língua portuguesa e matemática, um programa onde podemos montar diferentes aulas (P13).

Verificou-se que as tecnologias digitais estão sendo compreendidas e apropriadas como instrumentos pedagógicos complementares às práticas pedagógicas já estabelecidas, os quais possibilitam a produção de uma aula mais atrativa e interessante.

Segundo Soares, Valentin e Pescador:

(...) ao introduzirmos os laptops educacionais nas salas de aula, precisamos pensar em alternativas que estejam além do simples uso de tecnologias como um recurso para modernizar as práticas vigentes. Eles devem ser vistos especialmente como uma possibilidade de práticas inovadoras que favorecem o desenvolvimento de cooperação, autonomia, criticismo e construção de significado. (2013, p. 154)

A lousa digital, por exemplo, pode ser utilizada na sua potencialidade pedagógica, ou simplesmente como suporte visual de texto, imagens e vídeos. Do mesmo modo, os netbooks podem ser introduzidos na sala de aula simplesmente para a pesquisa de algum assunto ou ainda para a utilização de jogos educativos. Assim, a falta de orientação metodológica quanto ao uso das novas tecnologias educacionais nos cursos de formação inicial e de capacitação (formação continuada), é um dos fatores que contribuem para determinar a forma como os professores se apropriam dos recursos digitais em sala de aula.

\section{A formação de professores e as novas tecnologias: uma questão emergente}

É inconteste que a formação docente (inicial e continuada) constitui-se em um dos aspectos fundamentais do processo de ensino aprendizagem na escola. Talvez seja este um dos principais desafios quando o assunto é a introdução das novas tecnologias educacionais na escola de hoje.

Os professores entrevistados indiciaram em suas falas a problemática da falta de formação para o uso das tecnologias digitais na escola. O contexto escolar investigado revelou que a maioria dos professores não teve em sua formação inicial qualquer orientação técnica, teórica ou metodológica para o uso das novas tecnologias. Os 
professores afirmaram que não obtiveram conhecimentos específicos, e indicaram que as noções adquiridas para o uso das novas tecnologias, ocorreram de forma autodidata (gráfico 5).

Gráfico 5

Formação inicial dos professores

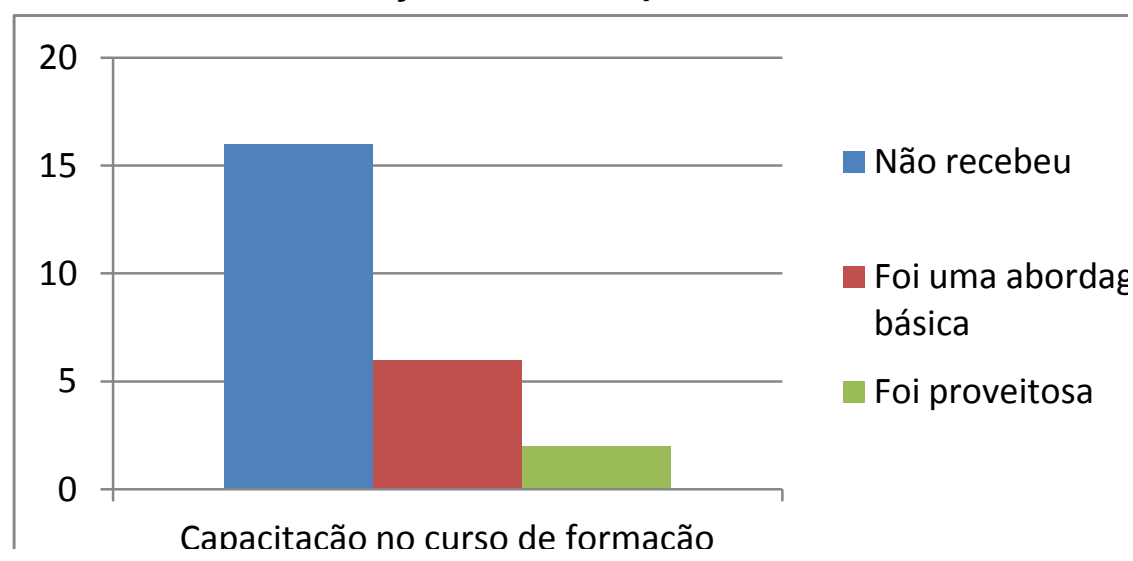

Fonte: Resultado da pesquisa realizada em escolas públicas em 2013.

No caso da formação continuada, poucos professores atribuem à aquisição de algum conhecimento nessa área à formação continuada e aos cursos de aprimoramento. Os professores que receberam cursos de capacitação específica, oferecidos pela mantenedora, relataram que o seu conteúdo se relacionava ao uso da tecnologia disponível, bem como do modo como se deveria manuseá-la no espaço da sala de aula, mas sem aprofundamento no que tange à abordagem metodológica (gráfico 6).

\section{Gráfico 6}

\section{Formação continuada dos professores para as novas tecnologias}

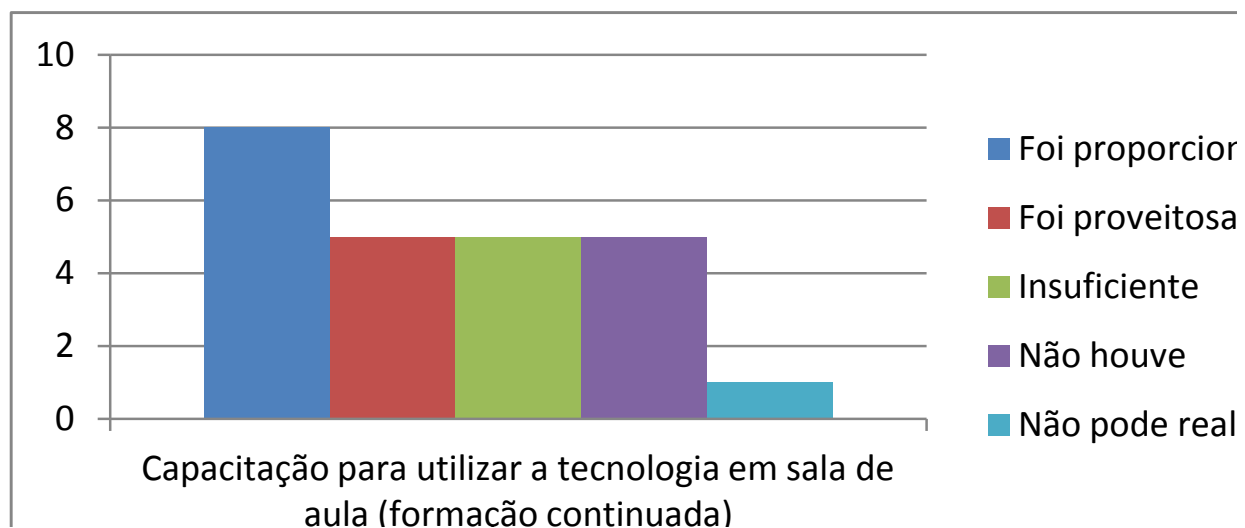

Fonte: Resultado da pesquisa realizada em escolas públicas em 2013. 
A formação do professor deve proporcionar a integração da informática nas atividades realizadas em sala de aula, promovendo as condições para se construir conhecimento. O professor deve entender que o computador pode ser integrado na sua prática pedagógica diária como um recurso que possibilita alcançar os objetivos pedagógicos a que se dispõe atingir. Pela falta de compreensão de como os recursos digitais podem propiciar a construção do conhecimento por meio de uma transformação metodológica, alguns professores consideram os recursos digitais na escola como instrumentos que geram medo e desconfiança.

Para Kenski, a formação dos professores para o uso das novas tecnologias deve:

Identificar quais as melhores maneiras de usar as tecnologias para abordar um determinado tema ou projeto específico ou refletir sobre eles, de maneira a aliar as especificidades do "suporte" pedagógico (do qual não se exclui nem a clássica aula expositiva nem, muito menos, o livro) ao objetivo maior da qualidade da aprendizagem de seus alunos. (2007, p. 106)

Um dos desafios da formação dos professores para o uso das novas tecnologias é desenvolver nos professores a capacidade para perceber a potencialidade dos recursos educacionais digitais. Essa concepção vai além daquela predominante nos cursos de formação docente, da qual põe em evidencia o treinamento para o manuseio correto do computador, deixando de lado o potencial metodológico da ferramenta. Esse foi o principal aspecto a ser apontado pelos professores no processo de formação docente: a falta de aporte metodológico para a utilização dos recursos digitais no processo de ensino aprendizagem.

Impondo novos ritmos e habilidades no processo de ensinar e aprender, as transformações tecnológicas da nossa sociedade têm sido muito céleres. Neste sentido, os professores devem ter pleno domínio do uso dos computadores.

Assim, continua Kenski:

Os usos de diferentes tecnologias digitais, por exemplo, em cursos presenciais, demandam novas habilidades dos docentes, além de estratégias e dinâmicas diversificadas para apresentação em sala de aula. Muita coisa muda: desde a apresentação e a organização dos conteúdos, até a realização de atividades, a distribuição dos tempos, a definição das formas de participação de professores e alunos e o processo de avaliação. (2007, p. 111) 
As novas tecnologias, recontextualizadas para o ambiente escolar, têm se caracterizado como um imprescindível instrumento de mediação pedagógica. Observouse, portanto, que a maioria dos professores, apesar de seus receios, limites e compreensão, tem demonstrado esforços para utilizar com o maior proveito possível as potencialidades pedagógicas das tecnologias digitais.

Contudo, a preocupação e a promoção de uma formação inicial e continuada dos professores para o uso das novas tecnologias deve ser o principal desafio da escola contemporânea. A formação docente deve proporcionar à escola as transformações necessárias da prática pedagógica. Uma prática que deve acompanhar a rápida difusão e acesso aos saberes produzidos pela cibercultura, sem perder de vista a formação humana baseada nos saberes acumulados historicamente.

\section{Considerações finais}

O presente trabalho procurou investir na ideia de que a presença das novas tecnologias educacionais na escola possibilita a atualização das práticas de ensino, por meio dos modos como os sujeitos escolares representam e se apropriam delas. Essas representações e apropriações materializadas nas práticas são capazes de produzir uma nova cultura escolar.

O questionamento lançado por Lévy no excerto abaixo, possibilita refletir sobre uma questão visualizada nos contextos escolares atuais. $O$ autor questiona e responde:

Como manter as práticas pedagógicas atualizadas com esses novos processos de transação de conhecimento? Não se trata aqui de usar as tecnologias a qualquer custo, mas sim de acompanhar consciente e deliberadamente uma mudança de civilização que questiona profundamente as formas institucionais, as mentalidades e a cultura dos sistemas educacionais tradicionais e sobretudo os papéis de professor e aluno. (Lévy, 1999, p. 174)

Nesta direção, entende-se que a transformação pedagógica a partir das novas tecnologias na sala de aula não é garantida somente pela inserção dos recursos digitais na escola, mas aos modos como os sujeitos escolares representam, se apropriam e recriam novas práticas.

A partir do estudo empírico, podemos conceber a representação e a apropriação dos professores quanto ao uso das tecnologias digitais na escola a partir de três 
categorias: a) as docentes representam as tecnologias digitais disponíveis como instrumentos complementares da prática pedagógica diária e atribuem a elas 0 desenvolvimento do caráter lúdico da aula, possibilitando maior concentração dos alunos nas atividades desenvolvidas; b) a apropriação dos recursos digitais redimensiona o espaço e o tempo da sala de aula, quando os alunos utilizam os netbooks e tem disponível a lousa digital; c) um dos grandes desafios da prática diária é a pouca habilidade para utilizar as novas tecnologias no desenvolvimento de novas metodologias educativas, em decorrência da falta de uma formação docente inicial e continuada.

No que se refere à representação, a maioria dos professores considera e entende que o computador pode ser muito relevante no processo de ensino aprendizagem, e o seu uso é fundamental para desenvolver atividades criativas e motivadoras, que vão de encontro com as necessidade e demandas da sociedade cibercultural. Para os professores, as novas tecnologias educacionais possibilitam: a melhor preparação do planejamento; uma aprendizagem de forma lúdica; maior concentração dos alunos nas aulas; ampliação do conteúdo trabalhado nas aulas.

Contudo, a falta de formação inicial e continuada tem se mostrado um dos principais aspectos negativos e um dos desafios fundamentais no processo de inserção das novas tecnologias na escola.

Assim, entre os aspectos negativos observado com este estudo, encontra-se a pouca infraestrutura das escolas para oferecer o suporte necessário às novas tecnologias educacionais e o pouco domínio metodológico por parte de alguns docentes no uso dos recursos digitais.

Planejar aulas diferentes e interativas, que mobilizem os alunos e possibilitem a inclusão na cultura digital, utilizando a lousa digital ou os netbooks, consiste ainda no principal desafio docente. Por isso, a utilização como suporte de texto, como reprodutor de vídeo ou instrumento de pesquisa ainda é uma representação que prevalece quando se pressupõe o uso do computador na sala de aula.

Ademais, é plausível afirmar que os desafios atuais impõem aos sujeitos escolares novas formas de lidar com o processo de ensino aprendizagem. O desencadear dessas novas maneiras de ensinar e aprender, impulsionadas pelas inúmeras transformações da sociedade da informação, permitirão que uma nova cultura escolar se constitua e se consolide, nos diversos níveis do sistema de ensino brasileiro. 
De acordo com os autores pesquisados e as respostas obtidas com a presente pesquisa, foi possível perceber que cada vez mais os computadores e recursos digitais portáteis adentram no cotidiano da escola. Assim, a escola inserida em uma sociedade cibercultural, por sua vez, não pode estar alheia às múltiplas formas em que constitui o acesso aos conhecimentos ora produzidos.

\section{Referências}

Barreto, Raquel Goulart. (2010). Configuração da política nacional de formação de professores à distância. Em Aberto, 23(84), 33-45.

Bonilla, Maria Helena Silveira. (2012). Software livre e formação de professores: para além da dimensão técnica. En Monica Fantin y Pier Cesare Rivoltella (orgs.) Cultura digital e escola: pesquisa e formação de professores (pp. 253-281). Campinas, São Paulo, Brasil: Papirus.

Fundo Nacional de Desenvolvimiento da Educaçao [FNDE]. (2010). Resolução FNDE/CD no 17 de junho de 2010. Recuperado de http://www.fnde.gov.br/fnde/legislacao/resolucoes/item/3399resolu\%C3\%A7\%C3\%A3o-cd-fnde-n\%C2\%BA-17-de-10-de-junho-de-2010

Chartier, Roger. (1991). O mundo como representação. Estudos Avançados, 5(11), 1-15.

Chizzotti, Antônio. (2000). Pesquisa em ciências humanas e sociais (4a. ed.). São Paulo, Brasil: Cortez.

Forquin, Jean-Claude. (1993). Escola e cultura: as bases sociais e epistemológicas do conhecimento escolar. Porto Alegre, Brasil: Artes Médicas.

Kenski, Vani Moreira. (1997). Novas tecnologias. O redimensionamento do espaço e do tempo e os impactos no trabalho docente. Revista Brasileira de Educação, 8, 58-71. Recuperado

de http://www.conhecer.org.br/download/INFORMATICA\%20EDUCATIVA/leitura\%20an exa\%203.pdf

Kenski, Vani Moreira. (2007). Educação e tecnologias: o novo ritmo da informação. Campinas, São Paulo, Brasil: Papirus.

Kenski, Vani Moreira. (2012). Tecnologias e ensino presencial e a distância. Campinas, São Paulo, Brasil: Papirus.

Lévy, Pierre (1999). Cibercultura. São Paulo: Editora 34. Recuperado de http://api.ning.com/files/dR26ICiX6Ej1UmSVtj1Qw9UvQlxgFXGXAUz9fUVc1ocygh1 WdsB9w8lbuWbUDbnD73S07wODeXavupVm5piQW20y8RQK2L7r/LevyCibercultur a.pdf 
Martins, Onilza Borges. (2008). Os caminhos da Ead no Brasil. Revista Diálogo Educacional, 8(24), 357-371. Recuperado de http://www.redalyc.org/articulo.oa?id=189116834004

Ribeiro, Lourdes; Oliveira, Maria; Mill, Daniel. (2013). Tecnologia e educação: aportes para a discussão sobre a docência na era digital. In Daniel Mill (org.), Escritos sobre Educação: desafios e possibilidades para ensinar e aprender com as tecnologias emergentes (pp. 137-164). São Paulo: Paulus.

Soares, Eliana Maria do Sacramento, Valentini, Carla Beatris y Pescador, Cristina Maria. (2013). O laptop educacional na escola pública: letramento digital e construção de significado. Educação Santa Maria, 38, 151-164. Recuperado de http://cascavel.ufsm.br/revistas/ojs-

2.2.2/index.php/reveducacao/article/viewFile/5624/4538

Viñao, Antônio. (2000). Sistemas educativos, culturas escolares y reformas. Madrid: Morata. 